\title{
Conditioned Intake and Fattening/Diabetes
}

\author{
Mario Ciampolini \\ Preventive Gastroenterology Unit, Department of Paediatrics, Università di Firenze, Florence, Italy \\ Email:mlciampolini@fastwebnet.it
}

Received 5 November 2015; accepted 20 December 2015; published 23 December 2015

Copyright (C) 2015 by author and Scientific Research Publishing Inc.

This work is licensed under the Creative Commons Attribution International License (CC BY).

http://creativecommons.org/licenses/by/4.0/

(c) (i) Open Access

\section{Abstract}

Background: Obesity, diabetes, asthma, autism, birth defects, dyslexia, attention deficit-hyperactivity disorder, and schizophrenia have increased in children in the last half century. The will (decision) to eat develops often when previous energy intake has been incompletely exhausted. objective: The will to eat develops after stimuli (often external) that do not correlate with energy availability in blood. Training a relation between hunger sensations (Initial Hunger, $\mathrm{IH}$ ) and Blood Glucose (BG) as an index of energy availability allows an IH Meal Pattern that is associated with low mean BG and insulin sensitivity. Lack of any relation between the will to eat and the energy availability is a widespread error that may be responsible of health deterioration in children as well as in adults. Methods: After meal suspension and with synchronous blood glucose (BG) measurements, we taught patients to distinguish hunger sensations that are conditioned from those that arise after meal suspension (Initial Hunger, IH). This hunger (after meal suspension) signals a complete exhaustion of previous intake and is appropriate for meal onset to obtain meal-by-meal fasting nutrient levels and low BG prior to the next meal and establish an even balance. This pattern has been termed the Initial Hunger Meal Pattern (IHMP). Results: In contrast with untrained control subjects, trained subjects accurately recognized IH by synchronous BG measurements. We report here the identification of Initial Hunger (the subjective limit), the daily adjustments to three arousals for weeks and months, the diffusion of the error in untrained child and adult population, the validations of the IH and BG assessments and the improvements of 18 parameters by IHMP. Conclusion: The will to eat develops as a conditioned event and this conditioned will causes positive energy imbalance and insulin resistance/fattening. The imbalancing will to eat may be corrected by becoming aware of differences between the conditioned sensations of hunger and the sensations that develop after meal suspension.

\section{Keywords}

Even Energy Balance, Initial Hunger, Blood Glucose, Energy Intake, Insulin Resistance, Fattening

\section{Introduction}

Energy imbalance is the result of an intake larger than the expenditure that leads to overweight, insulin resis-

How to cite this paper: Ciampolini, M. (2015) Conditioned Intake and Fattening/Diabetes. Open Journal of Preventive Medicine, 5, 468-478. http://dx.doi.org/10.4236/ojpm.2015.512053 
tance and diabetes. Energy imbalance is associated with an overall immune overstimulation (Sterile inflammation or proinflammatory state [1]-[12]) with vascular and liver diseases, allergies, autoimmunity and some malignant diseases [12]-[14]. In the last half century, obesity and diabetes have increased in children as well as asthma, autism, birth defects, dyslexia, attention deficit-hyperactivity disorder, and schizophrenia [15]. We have attributed the increased energy intake to an incomplete exhaustion of previous meal energy at each meal. The will to eat develops after many different conditioned signals when the exhaustion of previous energy intake is incomplete. Before meals, people have poor awareness on current available energy and this poor awareness is widespread. By synchronous blood glucose (BG) measurements, we taught patients to distinguish hunger sensations that are conditioned from those that arise after meal suspension. We used this hunger (after meal suspension) as a signal for the onset of the meals. This pattern was termed Initial Hunger Meal Pattern (IHMP), to obtain meal-by-meal fasting nutrient levels and low BG prior to the following meal [16]-[20].

This review aimed at giving a rapid and compressive outlook on our published demonstrations that are all convergent. Conditioned intake is not limited to overweight people and gastroenterology patients but appears to be as a global, durable, although correctable, health impairment that either activates or worsens inflammation in this or other organ till its devastation [21] [31]. Some authors have already reproduced our training [32] [33]. In infants, Birch independently, instructed mothers like we did [42] [43]. BG measurements suffice at proofing the reliability of the subjective sensations in different people [20] [23]. Yet, these measurements before any energy supply brought us into the unexplored area of energy availability. The excessive availability is the most influential factor [21]-[24] on pathogenic responses (overall subclinical inflammation) and on differences in life outcomes [1]-[15].

\section{Materials and Methods}

We assumed preprandial BG as an index of energy availability in blood and in all tissues [16]-[41] and conceived BG measurement as a check of the physiological background (energy availability) during hunger. At IH arousal, the same background (BG) suggested an accurate recognition of hunger sensation. BG provided an evaluation of energy intake and energy balance meal by meal: a repeatedly low fasting BG meant an even energy balance, whereas a high preprandial BG suggested a positive energy imbalance even if preprandial BG was steady [34]-[40]. We calculated the "Mean BG" from weekly diaries to notice differences in different both times and people. We lastly searched for associations with health and disease. This report is a summary of published papers that report much more details.

We studied infants between 6 months and 3 years of age with chronic/recurrent diarrhea. Many were clinically healthy and 9 were undernourished [24]. All were hospitalized in the Unity of Pediatric Gastroenterology in the Pediatric Department of the University of Florence for one or more days or even many months in follow-up studies up to twelve years between 1980 and 2000 [16]-[21]. We excluded food allergy by using the paper radio immunosorbent test and by measurement of total IgE [16] [17]. We screened the feces of all infants for parasites and viral or bacterial pathogens. Those who were positive were excluded. C-reactive protein was normal. Celiac disease was excluded by measuring antibodies against tTG and/or intestinal biopsy. The group of diarrheic, malnourished, not celiac infants (2 to 15 months of age) was separately studied in a follow-up for two years.

\subsection{Studies in Adults}

After the first diagnoses of celiac disease, the Unit received and treated also adults. Subjects were assigned concurrently and randomly to either a control or a treatment group. The local hospital ethics committee approved the investigations in compliance with the Declaration of Helsinki. Informed consent was obtained from parents for all the infants. At recruitment, a list assigned the infants randomly (using Armitage odd and even numbers) to either the training group or the control group. Briefly, the Pediatric Gastroenterology Unit of Florence University recruited 149 subjects who completed a 5 months follow-up from 1996 to 2000 [28]. Aged 18 - 60 years old, subjects suffered from symptoms of functional bowel disorders such as dyspepsia, abdominal pain, and diarrhea but were otherwise clinically healthy. Informed consent had been signed by all subjects. The local Hospital Ethics Committee approved the investigation in compliance with the Helsinki Declaration. Before recruitment, we prepared a list of blocks of 1 - 4 empty places. In a ratio of 1:3 blocks, we randomly assigned the blocks of empty places to either control or training groups by using Armitage odd and even random numbers. A dietician kept the list and subsequently assigned each recruited subject to the first empty list place. Control or 
training destination was revealed to the researchers after the first visit. Attrition (drop outs) was modest [32], always lower than 20\%. Clinical assessments were performed at initial and final visits and twice in the intervening 4 - 7 months follow-up period. The assessment se valuated compliance, nutritional intake and the subject's clinical condition. Written diaries were kept for a week before each clinical visit to evaluate IH arousal 3 or 4 times a day, preprandial BG three times a day, and relative adaptations in energy and fiber intake and in hours spent either in bed or in a gym plus outdoors. The number of subjects for each study was calculated to find differences with a power of $95 \%$ and an alpha of 0.05 . Further details are reported in each published article. Between 1995 and 2000, overweight adults or adults with functional bowel disorders came to the Unit for diagnostic purposes (mainly Celiac disease) and for treatment. A total of 181 subjects aged between 18 and 60, clinically healthy, were recruited for a treatment by IHMP. We randomly assigned all subjects to controlled studies in which the primary output was weight [23] [24] [28] [32]. One-hundred and forty-nine adults completed the study on body weight and 120 adults completed a second study where the primary output was an increase in insulin sensitivity [22] [23] [29].

\subsection{Statistical Methods}

In a previous study, we found an insulin sensitivity index in the intervention group $3 \mathrm{mg} / \mathrm{dL}$ higher than in the control group, with an SD of 3.0 [29]. Based on these figures, our sample size calculations suggested that we need a minimum of 14 subjects in each comparison group to detect a similar difference between index means, with a power of $80 \%$ and a unilateral alpha of 0.05 . Values are expressed as mean \pm SD. Twenty-one diarized BG measurements had a normal distribution around the mean. Confidence intervals were calculated to include 95\% of measurements [22]. Stratification of 120 subjects by mean BG and search for the cutoff point at recruitment between subjects who significantly responded to “recognizing hunger” by mean BG and non responders was discussed in the Statistics Department of the University of Firenze (see Acknowledgments). In the separate LBG and HBG subgroups, a logistic regression analysis investigated the association of the training and BG mean, Hb1c, insulin and BG AUCs, intakes, and anthropometric measures (trained vs untrained control groups) to overcome doubts on significance of multiple results. Collinearity diagnostics and residual analysis validated the statistical model. The significance of difference and correlation was set at $\mathrm{P}<0.05$ in these analyses. Yates test and two-tailed Student's t-test on paired or unpaired samples according to data requirements were used to analyze the significance of difference and two-tailed Student's t-test for correlation. The significance was set at $\mathrm{P}<0.05$ for single measurements and at $\mathrm{P}<0.025$ for the GTT insulin and BG AUCs [20]. The trials on wellbeing, nutrition, and cardiovascular risks comprised five to seven tests each. The significance was set at $\mathrm{P}<0.01$ for the outcome of a single measurement within these trials. The Bonferroni correction was applied when required in the evaluation of multiple comparison results. In multiple analyses, the "<” symbol indicates the least significant P-value. Specially provided software was used to tabulate data for statistical analyses. Microsoft Excel and SAS (v 8; SAS Institute, Inc, Cary, NC) were used for data presentation and for statistical analyses.

\subsection{Initial Hunger}

Initial Hunger (IH) emerged after meal suspension as a biophysical, subjective sensation that coincided with a repeatedly recognizable physiological state of diminished energy availability. The physiological state recurred sometimes per day and suggested spontaneously energy intake in absence of visual, smell or word food cues [16]-[20]. At IH recognition, BG identified energy availability (see later). A first study assessed the recognition of hunger in the hospital lab. Seventy-two control adults and 64 trained adults completed the two month followup. We checked the learning by comparing the estimated BG and the BG measured by autoanalyzer [18]. An independent laboratory studied ten adults and confirmed our results [33].

\subsubsection{Training Protocol}

1) Suspend meals for up to 48 hours.

2) Locate physical sensation of hunger.

3) Measure blood glucose concentration (BG).

4) Mentally associate the physical sensation with the BG concentration.

5) Begin with a meal of about $300 \mathrm{kcal}$.

6) Repeat 1 - 5 increasing the meal size in proportion to the desired inter-meal interval. 
7) Repeat the above procedure for two weeks. At each appearance of physical hunger, compare the sensation and the measured BG with the previous sensations.

Fat calories are burned and stored several times more slowly than non-fat calories [37]-[40]. There were large differences among the utilizations of fatty acids. We assumed that BG was representative, as an index, of total energy availability for body tissues in the studied, clinically healthy, subjects with carbohydrate intake between $50 \%$ and $60 \%$ of total energy intake [34]-[40]. Vegetables and fruit were suggested in an amount between 500 and 1000 grams per day over 8 years of age. This amount prevented BG depressions in hyperinsulinemic subjects who wanted to decrease body weight [31].

\subsubsection{Validity of a Portable Device for BG Measurements}

The training was accomplished by home BG preprandial measurements, with a portable device (a portable potentiometer for whole BG measurement with the exokinase method: Glucocard Memory; Menarini Diagnostics; Florence, Italy). The subject had to personally measure BG with the portable instrument against the autoanalyzer in the lab as he/she did at home. At blood sampling, we supervised the performance of the comparison. The autoanalyzer was checked every morning in comparison with the other 50 laboratories in Tuscany. A difference in BG from the mean had to remain within $1 \%$ every day. The heparinized blood sample for the autoanalyzer was immediately centrifuged and measured with the exokinase method. In the meantime, the patient performed his/her measurements on the same blood sample by glucometer. The autoanalyzer obtained a mean \pm SD of 89.9 $\pm 11.3 \mathrm{mg} / \mathrm{dL}(\mathrm{N}=85)$. Subjects measured $89.0 \pm 12.5 \mathrm{mg} / \mathrm{dL}$. The mean difference $(0.9 \pm 7.1)$ was not significant. On absolute values, the mean difference was: $5.7 \pm 4.3 \mathrm{mg} / \mathrm{dL}$ with no bias. This error is low compared to the spontaneous BG wavering of $10 \%$ every 12 minutes [41].

\subsection{Checking the Training}

The training consisted in BG measurements at hunger arousal, lasted two weeks, and one month later 64 trained and 72 control, untrained subjects attended the hospital lab before breakfast after an overnight fasting [18]. All subjects declared current presence or absence of hunger, and estimated BG (Figure 1). A glucose autoanalyzer measured actual BG. All hungry subjects described hunger sensations as gastric emptiness or gastric pangs. In the hungry trained group, the mean estimated BG was 78.1 \pm 6.7 and the mean measured value was $80.1 \pm 6.3$ $\mathrm{mg} / \mathrm{dL}$ This measured BG was significantly lower than the measurements in hungry control subjects (89.2 \pm $10.2 \mathrm{mg} / \mathrm{dL})$ and in not-hungry subjects of both trained $(90.0 \pm 6.6 \mathrm{mg} / \mathrm{dL})$ and control $(90.6 \pm 10.9 \mathrm{mg} / \mathrm{dL})$ groups. The absolute value of the difference between estimated and measured glucose (estimation error) in the

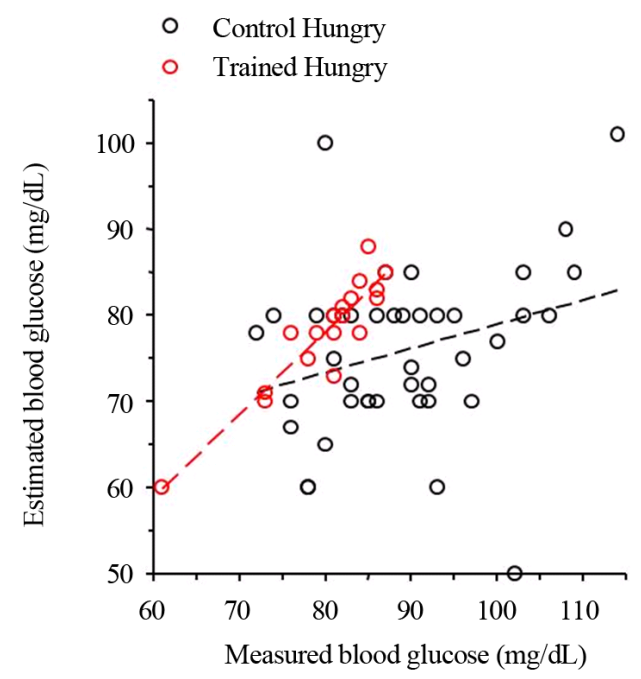

Figure 1. Subjects reporting hunger at the laboratory final investigative session. 42 untrained controls (black circles, $r=0.29$, NS) vs. 18 trained subjects (red circles), $r=0.93$, $\mathrm{P}=0.0001)$. Copyright (C) 2006, Dove Medical Press Ltd. Image courtesy of Ciampolini M, et al. [18]. 
hungry trained group $(3.2 \% \pm 2.4 \%$ of the measured value) was significantly lower than the one in the hungry control group $(16.7 \% \pm 11.0 \%)$. These findings prove that control (untrained) subjects do not reflect their biochemical condition when stating to be hungry and estimating BG. Trained subjects instead, show a low BG condition when hungry and estimate accurately their current energy availability. We repeated an uncontrolled study in children younger than three years of age.

In the hospital laboratory the autoanalyzer measured BG in 16 toddlers not demanding food before breakfast in comparison with 54 toddlers who were demanding food, all after training with 42 measurements at hunger arousal [17]. No demand was associated with a significantly higher BG than the condition of food demand (96.3 $\pm 10.5 \mathrm{mg} / \mathrm{dL}$ versus $74.6 \pm 7.7 \mathrm{mg} / \mathrm{dL} ; \mathrm{P}=0.0001)$. Based on these studies, the initial demand (ID or IH) was conceived as a threshold phenomenon triggered by low energy availability in blood, indicated by low BG; normal activity is not inhibited by low energy. The intervention may be conceived as an abrupt weaning of the mother and child from the automatic, scheduled feeding to implement a habitual evaluation of time and amount of meal.

\subsection{Differences between Conditioned Hunger and Hunger after Meal Suspension}

In the hospital lab, at the question on hunger, control, untrained subjects focused on food and developed gastroduodenal Pavlovian reflexes that are weaker and shorter than the sensations after eating suspension. The main difference is at the sensation onset: either before focusing on food (after meal suspension) or after focusing on food (conditioned). Low BG can confirm the distinction.

\section{Results}

IHMP changes energy availability in blood and in all tissues (Table 1). BG is a good index in people that draw more than 50\% of their energy from carbohydrates [34]-[40]. Preprandial BG informs also on energy balance when the will to eat emerges. A mean in a sequence (Mean BG) informs us on the energy balance and on the maintenance of distance from fattening/Ins Res in that period. In 120 adults at recruitment, Mean BG is stratified in ten strata with a small confidence interval around the mean $(3.8 \mathrm{mg} / \mathrm{dL})$ and values were stable after 5 months in 31 control, untrained adults. In controlled studies during IHMP, we found significant decreases of:

1) Mean BG in 143 infants [17], and in 149 adults [28]; 2) plasma triglycerides in 9 undernourished infants [19]. 3) glycated hemoglobin in 120 adults [22]; 4) energy availability is associated with resting metabolic rate and total daily expenditure. These values decreased in 24 infants by indirect calorimetry and doubly labelled water [20]. This decrease is reminiscent of the lower energy expenditure by breast-fed infants in comparison to formula fed infants [44] [45]. The decreases in Mean BG and in RMR are not uniform among children and adults but are in significant positive correlation with the Mean BG at recruitment $(\mathrm{r}=0.75 ; \mathrm{N}=89 ; \mathrm{P}=0.0001$, Figure 2); 5) No variation of the lowest Mean BGs, about one third of investigated children or adults [17] [22]. This "freely chosen" BG level at recruitment is identical to the level obtained by children and adults who show significant decreases after training $(76.6 \pm 3.7 \mathrm{mg} / \mathrm{dL})$ [22], In sedentary people, this BG represents the fasting value associated with an even balance (maintenance of weight and insulin sensitivity; 6) SD of BG during a diary week [22]; 7) energy intake: this becomes a variable targeted to the steady maintenance of preprandial fasting BG [16] [17] [22]; 8) Triglycerides [16] [17] [20] [22]; 9) total cholesterol to HDL choletsterol ratio [22]; 10) diastolic blood pressure [22]; 11) number of days with diarrhea or abdominal pain [17] [22]; 12) Body weight and body mass index selectively in overweight adults and also normal-weight adults with high fasting mean BG (over about 82 mg/dL; Table 2) [18] [22] [32]; 13) arm and 14) leg skinfold thickness in overweight adults and in subjects with high fasting mean BG [18] [26]; 15) fecal energy emission by bomb calorimetry [46]; 16) Increase of insulin sensitivity index, only in subjects with high fasting mean BG [22], [47]; 17) increase of insulinogenic index [22] [48]; 18) maintenance of body weight of lean children and adults who have low fasting mean BG [28].

\section{Discussion}

Investigation on children, on adults and even on malnourished infants showed significantly higher preprandial Mean BG at recruitment than during IHMP for an incomplete exhaustion of BG and available nutrients in blood at meals (See triglycerides in malnourished infants). This elevation causes untoward reflexes in the small intestine [20] [49]. The training eliminated the unexhausted BG and the high preprandial BG decreased more in 


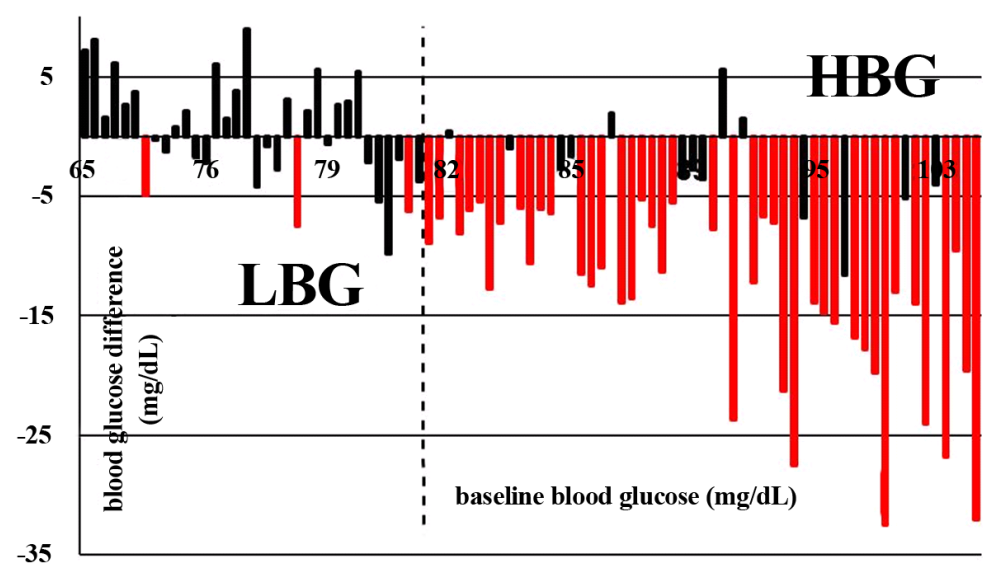

Figure 2. Decreases of mean pre-prandial BG after training versus Mean BG at recruitment for each trained subject. Notes: Abbreviations: BG, blood glucose; HBG, high blood glucose; LBG, low blood glucose. Column heights show Mean BG differences 5 months after recruitment in each trained subject. Significant increases are indicated by blue bars, significant decreases by red bars, and no significant changes by black bars. Mean BG is reported in sequentially increasing order at recruitment, not in linear correlation with segment length on the $\mathrm{X}$-axis scale. The vertical dashed line indicates the most significant division between subjects who showed no Mean BG decrease after training (low BG group, $n=34$ ) and those who showed a significant decrease of Mean BG (high BG group, $\mathrm{n}=55$; Chi-squared analysis: $\mathrm{P}=0.00001$ ). This $\mathrm{BG}$ threshold (demarcation point) is $81.8 \mathrm{mg} / \mathrm{dL}(4.54 \mathrm{mmol} / \mathrm{L})$ at recruitment. Subjects above this threshold affected most improvements in weight and insulin resistance. Copyright (C 2011, Dove Medical Press Ltd. Image courtesy of Ciampolini M, et al. [22].

Table 1. Over-weight groups at baseline and at investigation end. Composition, compliance and effects of training (IHMP) on diary reports and anthropometry.

\begin{tabular}{|c|c|c|c|c|}
\hline & \multicolumn{2}{|c|}{ Control } & \multicolumn{2}{|c|}{ Trained } \\
\hline & Baseline & After 5 mo. & Baseline & After 5 mo. \\
\hline Number of subjects and gender & \multicolumn{2}{|c|}{$13 \mathrm{~F}+8 \mathrm{M}$} & \multicolumn{2}{|c|}{$23 \mathrm{~F}+15 \mathrm{M}$} \\
\hline Schooling $^{1}$ & \multicolumn{2}{|c|}{$11.1 \pm 2.7$} & \multicolumn{2}{|c|}{$12.0 \pm 3.0$} \\
\hline Age $^{1}$ & \multicolumn{2}{|c|}{$33.7 \pm 14.4$} & \multicolumn{2}{|c|}{$36.7 \pm 12.6$} \\
\hline Subjects showing BG decrease ${ }^{2}$ & \multicolumn{2}{|c|}{ 3/21 (14.3\%) } & \multicolumn{2}{|c|}{$24 / 38(63.2 \%)^{* * *, a}$} \\
\hline BG group mean pre-meal ${ }^{3}$ & $85.7 \pm 9.0$ & $89.3 \pm 8.2^{*, \mathrm{~b}}$ & $86.8 \pm 8.7$ & $78.8 \pm 6.8^{* * *, a^{* * *}, \mathrm{~b}}$ \\
\hline Subjects $<81.8 \mathrm{mg} / \mathrm{dL}^{4}$ & $8(38.1 \%)$ & $5(33.8 \%)$ & $12(31.6 \%)$ & $29(76.3 \%)^{* * *, a^{* * *, b}}$ \\
\hline Vegetable intake $^{5}$ & $246 \pm 188$ & $427 \pm 263^{* *, \mathrm{~b}}$ & $274 \pm 166$ & $449 \pm 218^{* * *, \mathrm{~b}}$ \\
\hline Fruit intake $^{5}$ & $193 \pm 155$ & $173 \pm 160$ & $221 \pm 122$ & $266 \pm 174$ \\
\hline Energy intake $^{6}$ & $1728 \pm 551$ & $1310 \pm 532^{* *, \mathrm{~b}}$ & $1756 \pm 585$ & $1069 \pm 487^{* * *, \mathrm{~b}}$ \\
\hline Diary BG SD ${ }^{7}$ & $8.9 \pm 4.2$ & $8.9 \pm 3.8$ & $9.6 \pm 4.8$ & $6.4 \pm 3.6^{* *, \mathrm{a}^{* * *}, \mathrm{~b}}$ \\
\hline $\mathrm{BMI}^{8}$ & $29.1 \pm 5.6$ & $28.2 \pm 5.6^{*, \mathrm{~b}}$ & $28.7 \pm 3.5$ & $26.5 \pm 3.5^{* *, \mathrm{a}^{* * *, \mathrm{~b}}}$ \\
\hline Weight $^{9}$ & $76.1 \pm 16.6$ & $73.8 \pm 16.2^{*, \mathrm{~b}}$ & $78.0 \pm 10.2$ & $72.2 \pm 10.1^{*, \mathrm{~b}}$ \\
\hline Arm skinfold thickness ${ }^{10}$ & $25.4 \pm 10.0$ & $21.0 \pm 7.6^{* *, \mathrm{~b}}$ & $25.8 \pm 9.2$ & $19.9 \pm 7.7^{* * *, \mathrm{~b}}$ \\
\hline Leg skinfold thickness ${ }^{10}$ & $34.5 \pm 13.0$ & $29.7 \pm 10.7^{* *, \mathrm{~b}}$ & $32.1 \pm 12.6$ & $25.1 \pm 10.2^{* * *, \mathrm{~b}}$ \\
\hline
\end{tabular}

Notes: Values are expressed as means \pm SD. ${ }^{1}$ Years at the beginning of the study. ${ }^{2}$ Number of subjects who significantly decreased mean pre-meal diary BG. ${ }^{3}$ Mean pre-meal of diary blood glucose, $\mathrm{mg} / \mathrm{dL}, \mathrm{LBG}=$ lower than $81.8 \mathrm{mg} / \mathrm{dL}$. HBG $=$ higher than $81.8 \mathrm{mg} / \mathrm{dL}$. ${ }^{4} \mathrm{Number}$ of subjects who fell into the LBG at end of the study. ${ }^{5}$ grams/d. ${ }^{6} \mathrm{Kcal} / \mathrm{d}$. ${ }^{7}$ Diary BG SD refers to the SD of 21 BG preprandial measurements reported in $7 \mathrm{~d}$ diary by each subject. ${ }^{8}$ Body weight in kg/square height in meters. ${ }^{9} \mathrm{~kg}$. ${ }^{10} \mathrm{~mm}$. Asterisks indicate significant differences (Student's t-test or Yates test: ${ }^{*} \mathrm{P}<0.05$; $\left.{ }^{* *} \mathrm{P}<0.01 ;{ }^{* * *} \mathrm{P}<0.001\right)$ vs. respective control group values based on "post-pre” measurements (a), or vs. baseline values of the same group (b). 


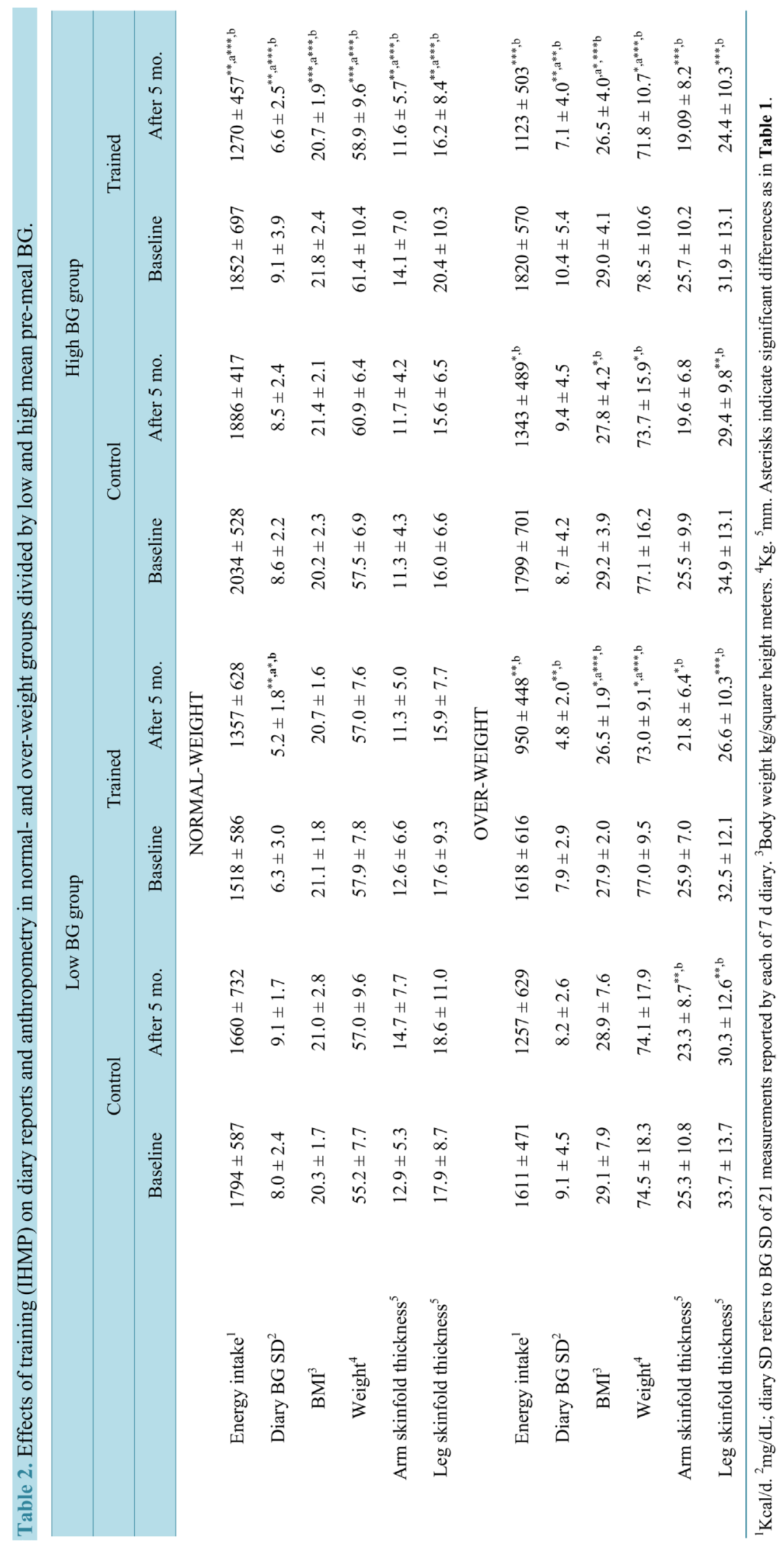


trained subjects in comparison with control subjects. At recruitment, about one third of both the investigated children and the investigated adults showed Mean BG, insulin sensitivity and HbA1c that were similar to the values of subjects after training. This identity suggests that training IHMP is a reacquisition of a safe, normal eating pattern that was developed in the phylogenesis rather than a technological artifact. In our findings, the sequence: conditioned intake, high preprandial BG (energy imbalance), fattening/Ins Res, sterile inflammation and health risks appears to be widespread to $60 \%$ of children and adults [17] [23]. Subjects at recruitment ignored their incompleteness of energy exhaustion and their comment was: "I would have known it earlier". They also ignored the immune deterioration by sterile inflammation and health risks that follow fattening/Ins Res [1]-[14]. We have under-investigated the development of sterile inflammation. We have shown that bacteria proliferate in proportion to the permanence of food in the small intestine [49] and we have found a decrease of IgG plasma antibody level against Helicobacter pylori and a prevention of infection during IHMP [27]. A suppression of functional bowel disorders during elimination of insulin resistance through IHMP also suggests elimination of sterile inflammation [17] [23] [26]. A large body of studies has shown the association of fattening/Ins Res with a worsening of infections, chronic functional disorders, autoimmunity and allergies [1]-[14]. The initial sensation of hunger ( $\mathrm{IH}$ ), that may be learned after meal suspension, may be used to reproduce a meal by meal even balance [32] and this reconstitution would be more effective than any assistance provided by governments.

We studied children and adults that were clinically healthy (motivated by functional disorders), overweight people and infants with malnutrition. This suggests that the conditioned eating and its remedy by awareness on BG might interest anybody. This is not true. At recruitment, part of "healthy" infants and adults presented the same BG as the BG of trained subjects. The not studied population might be in either worse or better condition. Compliance and effects of IHMP in healthy, ill or diabetic subjects are poorly known. This opens a large field of investigation and treatment on the conditions associated with fattening/Ins Res.

\section{Conclusion}

Infant/mother pairs recognize easily IH without BG measurements [17] [20]. Adults can learn the recognition in few days (Figure 1), and meals allowing three IH arousals per day are associated with an even energy balance (Figure 2). This meal pattern may become the reference for normal energy intake and for normal/ideal body weight. Repeating the recognition of IH sensation after the first initial meal suspension requires, in adults, a validation by the preprandial measurement of BG. This measurement may be repeated after months and years to check the identity in recognition. Diabetics, old and overweight people with poor insulin production may not feel hunger at all [22] [23] [26]. The relation between vegetable intake, energy intake and mean BG requires a study ad hoc [28].

\section{Acknowledgements}

The Author acknowledges the indispensable collaboration in writing with David Lowel-Smith (NZ) and Riccardo Bianchi (NY), and the strategic, statistical support by Cutberto Garza (Rector, Boston College), Giuliano Parrini (Professor of Physics, Firenze) and Andrea Giommi (Professor of Statistics, Firenze).

The here summarized researches were supported by the Italian Ministry of University, Research, Science and Technology grants for the years 1998-2002 and by ONLUS Nutrizione e Prevenzione, Firenze, for the years 2003-2012. No conflicts of interest.

This review has been shown in: "Modifying Eating Behavior: Novel Approaches for Reducing Body Weight, Preventing Weight Regain and Reducing Chronic Disease Risk” ASN’s Annual Meeting \& Scientific Sessions at Experimental Biology 2014, April 26-30.

\section{Conflict of Interests}

No conflicts of interest.

\section{References}

[1] Reaven, G.M. (1988) Role of Insulin Resistance in Human Disease. Banting Lecture 1988. Diabetes, 37, $1595-1607$. http://dx.doi.org/10.2337/diab.37.12.1595 
[2] Brandtzaeg, P., Halstensen, T.S., Kett, K., Krajci, P., Kvale, D., et al. (1989) Immunobiology and Immunopathology of Human Gut Mucosa: Humoral Immunity and Intreaepithelial Lymphocytes. Gastroenterology, 97, 1562-1584.

[3] Hecht, G. (2007) In the Beginning Was Helicobacter pylori: Roles for Microbes in Other Intestinal Disorders. Gastroenterology, 132, 481-483. http://dx.doi.org/10.1053/j.gastro.2007.01.013

[4] Festa, A., D’Agostino Jr., R., Howard, G., Mykkanen, L., Russell, P.T., et al. (2000) Chronic Subclinical Inflammation as Part of the Insulin Resistance Syndrome: The Insulin Resistance Atherosclerosis Study (IRAS). Circulation, 102, 42-47. http://dx.doi.org/10.1161/01.CIR.102.1.42

[5] Reaven, G.M. (2006) The Metabolic Syndrome: Is This Diagnosis Necessary? American Journal of Clinical Nutrition, 83, 1237-1247.

[6] Smith, C.W. (2007) Diet and Leukocytes. American Journal of Clinical Nutrition, 86, 1257-1258.

[7] Bigorgne, A.E., Bouchet-Delbos, L., Naveau, S., Dagher, I., Prevot, S., et al. (2008) Obesity-Induced Lymphocyte Hyperresponsiveness to Chemokines: A New Mechanism of Fatty Liver Inflammation in Obese Mice. Gastroenterology, 134, 1459-1469. http://dx.doi.org/10.1053/j.gastro.2008.02.055

[8] Cani, P.D., Amar, J., Iglesias, M.A., Poggi M., Knauf, C., et al. (2007) Metabolicendotoxemia Initiates Obesity and Insulin Resistance. Diabetes, 56, 1761-1767. http://dx.doi.org/10.2337/db06-1491

[9] Stratton, I.M., Adler, A.I., Neil, H.-A.W., Yudkin, J.S., Matthews, D.R., et al., on Behalf of the UK Prospective Diabetes Study Group (2000) Association of Glycaemia with Macrovascular and Microvascular Complications of Type 2 Diabetes (UKPDS 35): Prospective Observational Study. British Medical Journal, 321, 405-412. http://dx.doi.org/10.1136/bmj.321.7258.405

[10] Bruun, J.M., Verdich, C., Toubro, S., Astrup, A. and Richelsen, B. (2003) Association between Measures of Insulin Sensitivity and Circulating Levels of Interleukin-8, Interleukin-6 and Tumor Necrosis Factor-Alpha. Effect of Weight Loss in Obese Men. European Journal of Endocrinology, 148, 535-542. http://dx.doi.org/10.1530/eje.0.1480535

[11] Bragg, F., Li, L., Smith, M., Guo, Y., Chen, Y., et al., China Kadoorie Biobank Collaborative Group (2014) Associations of Blood Glucose and Prevalent Diabetes with Risk of Cardiovascular Disease in 500,000 Adult Chinese: The China Kadoorie Biobank. Diabetic Medicine, 31, 540-551. http://dx.doi.org/10.1111/dme.12392

[12] Kubes, P. and Meahl, W.Z. (2012) Sterile Inflammation in the Liver. Gastroenterlogy, 143, 1158-1172. http://dx.doi.org/10.1053/j.gastro.2012.09.008

[13] Calle, E.E., Rodriguez, C., Walker-Thurmond, K. and Thun, M.J. (2003) Overweight, Obesity, and Mortality from Cancer in a Prospectively Studied Cohort of U.S. Adults. The New England Journal of Medicine, 348, 1625-1638. http://dx.doi.org/10.1056/NEJMoa021423

[14] Fontana, L., Klein, S. and Holloszy, J.O. (2006) Long-Term Low-Protein, Low-Calorie Diet and Endurance Exercise Modulate Metabolic Factors Associated with Cancer Risk. The American Journal of Clinical Nutrition, 84, 1456-1462.

[15] Landrigan, P.J. and Baker, B. (2015) The National Children's Study-End or New Beginning? The New England Journal of Medicine, 372, 1486-1487. http://dx.doi.org/10.1056/NEJMp1500276

[16] Ciampolini, M., Vicarelli, D. and Seminara, S. (1990) Normal Energy Intake Range in Children with Chronic NonSpecific Diarrhea. Association of Relapses with the Higher Level. Journal of Pediatric Gastroenterology \& Nutrition, 11, 342-350. http://dx.doi.org/10.1097/00005176-199010000-00010

[17] Ciampolini, M. (2012) Requested Meals versus Scheduled Meals. International Journal of General Medicine, 5, 345353. http://www.dovepress.com/article 12104.t15115810

http://www.ncbi.nlm.nih.gov/pubmed/23393411 http://dx.doi.org/10.2147/ijgm.s29889

[18] Ciampolini, M. and Bianchi, R. (2006) Training to Estimate Blood Glucose and to Form Associations with Initial Hunger. Nutrition \& Metabolism, 3, 42. http://www.nutritionandmetabolism.com/content/3/1/42 http://dx.doi.org/10.1186/1743-7075-3-42

[19] Ciampolini, M., Bianchi, R. and Sifone, M. (2014) "Initial Hunger” for All? A Study on Undernourished Infants. Journal of Pediatrics \& Neonatal Care, 1, 00008. http://dx.doi.org/10.15406/jpnc.2014.01.00008

[20] Ciampolini, M., Brenna, J.T., Giannellini, V. and Bini, S. (2013) Interruption of Scheduled, Automatic Feeding and Reduction of Excess Energy Intake in Toddlers. International Journal of General Medicine, 6, 39-47. http://dx.doi.org/10.2147/IJGM.S39946

[21] Ciampolini, M. (2013) Interruption of Automatic Feeding, of Fattening and Associated Immune Deficiency. Recent Research Developments in Nutrition, 9. http://www.ressign.com/UserBookDetail.aspx?bkid=1337\&catid=291

[22] Ciampolini, M. and Sifone, M. (2011) Differences in Maintenance of Mean Blood Glucose (BG) and Their Association with Response to "Recognizing Hunger". International Journal of General Medicine, 4, 403-412. http://dx.doi.org/10.2147/IJGM.S19035 
[23] Ciampolini, M., Lovell-Smith, H.D., Kenealy, T. and Bianchi, R. (2013) Hunger Can Be Taught: IHMP Regulates Eating and Improves Energy Balance (Review). International Journal of General Medicine, 6, 465-478. http://www.dovepress.com/articles.php?article_id=13355 http://dx.doi.org/10.2147/IJGM.S40655

[24] Ciampolini, M. (2014) New Findings on Energy Balance and Established Wisdom. International Journal of Nutrition and Food Sciences, 3, 300-306. http://dx.doi.org/10.11648/j.ijnfs.20140304.20

[25] Ciampolini, M., Becherucci, P., Vicarelli, D., Seminara, S., Bini, S., et al. (1991) Decrease in Serum IgE Associated with Limited Restriction in Energy Intake to Treat Toddler's Diarrhea. Physiology \& Behavior, 49, 155-160. http://dx.doi.org/10.1016/0031-9384(91)90248-M

[26] Ciampolini, M., Bini, S., Giommi, A., Vicarelli, D. and Giannellini, V. (1994) Same Growth and Different Energy Intake in Chronic Non-Specific Diarrhea Children in a Four-Year Period. International Journal of Obesity, 18, 17-23.

[27] Ciampolini, M., Borselli, L. and Giannellini, V. (2000) Attention to Metabolic Hunger and Its Effects on Helicobacter pylori Infection. Physiology \& Behavior, 70, 287-296. http://dx.doi.org/10.1016/S0031-9384(00)00273-0

[28] Ciampolini, M., Lovell-Smith, D. and Sifone, M. (2010) Sustained Self-Regulation of Energy Intake. Loss of Weight in OW Subjects. Maintenance of Weight in Normal-Weight Subjects. Nutrition \& Metabolism, 7, 4. http://www.nutritionandmetabolism.com/content/7/1/4 http://dx.doi.org/10.1186/1743-7075-7-4

[29] Ciampolini, M., Lovell-Smith, D., Bianchi, R., de Pont, B., Sifone, M., et al. (2010) Sustained Self-Regulation of Energy Intake: Initial Hunger Improves Insulin Sensitivity. Journal of Nutrition and Metabolism, 2010, Article ID: 286952. http://www.hindawi.com/journals/jnume/aip.286952.html http://dx.doi.org/10.1155/2010/286952

[30] Ciampolini, M. (2012) Eliciting Clear-Cut Initial-Hunger at Proper Time. OMICS Publishing Group, Hyderabad.

[31] Ciampolini, M. and Lovell Smith, D. (2014) Self-Regulation of Food Intake and Energy Balance. A Handbook. Lambert Academic Publishing, Saarbrücken, 35. https://www.lap-publishing.com/.../978-3-8473-7027-7

[32] Ledoux, T., Gallagher, M.R., Ciampolini, M. and Sampson, M. (2014) Biofeedback Enhanced Lifestyle. Intervention: Exploring the Experience of Participants in a Novel Intervention for Disinhibited Eating and Obesity. Open Journal of Preventive Medicine, 4, 779-788. http://dx.doi.org/10.4236/ojpm.2014.410088

[33] Jospe, M.R., Brown, R.C. and Roy, M. (2015) Adherence to Hunger Training Using Blood Glucose Monitoring: A Feasibility Study. Nutrition \& Metabolism, 6, 12-22.

[34] de Graaf, C., Blom, W.A.M., Smeets, P.A.M., Stafleu, A. and Hendriks, H.F.J. (2004) Biomarkers of Satiation and Satiety. The American Journal of Clinical Nutrition, 79, 946-961.

[35] Gavin, J.R. (2001) Pathophysiologic Mechanisms of Postprandial Hyperglycemia. American Journal of Cardiology, 88, S4-S8. http://dx.doi.org/10.1016/S0002-9149(01)01830-6

[36] Elliott, S.S., Keim, N.L., Stern, J.S., Teff, K. and Havel, P.J. (2002) Fructose, Weight Gain, and the Insulin Resistance Syndrome. The American Journal of Clinical Nutrition, 76, 911-922.

[37] Swinburn, B.A. and Ravussin, E. (1994) Energy and Macronutrient Metabolism. Baillière’s Clinical Endocrinology and Metabolism, 8, 527-548. http://dx.doi.org/10.1016/S0950-351X(05)80285-X

[38] Westerterp, K.R. (2004) Diet Induced Thermogenesis. Nutrition \& Metabolism, 1, 5. http://dx.doi.org/10.1186/1743-7075-1-5

[39] Van Wymelbeke, V., Himaya, A., Louis-Sylvestre, J. and Fantino, M. (1998) Influence of Medium-Chain and LongChain Triacilglycerols on the Control of Food Intake in Men. The American Journal of Clinical Nutrition, 68, 226-234.

[40] Summers, L.K.M., Barnes, S.C., Fielding, B.A., Beysen, C., Ilic, V., et al. (2000) Uptake of Individual Fatty Acids into Adipose Tissue in Relation to Their Presence in the Diet. The American Journal of Clinical Nutrition, 71, 1470-1477.

[41] Campfield, L.A. and Smith, F.J. (2003) Blood Glucose Dynamics and Control of Meal Initiation: A Pattern Detection and Recognition Theory. Physiological Reviews, 83, 25-58. http://dx.doi.org/10.1152/physrev.00019.2002

[42] Fisher, J.O. and Birch, L.L. (2002) Eating in the Absence of Hunger and Overweight in Girls from 5 to 7 y of Age. The American Journal of Clinical Nutrition, 76, 226-231.

[43] Leahy, K.E., Birch, L.L. and Rolls, B.J. (2008) Reducing the Energy Density of Multiple Meals Decreases the Energy Intake of Preschool-Age Children. The American Journal of Clinical Nutrition, 88, 1459-1468. http://dx.doi.org/10.3945/ajcn.2008.26522

[44] Butte, N.F., Garza, C., O’Brian, S.E. and Nichols, B.L.V. (1984) Human Milk Intake and Growth in Exclusively Breast-Fed Infants. The Journal of Pediatrics, 104, 187-195. http://dx.doi.org/10.1016/S0022-3476(84)80990-7

[45] Butte, N.F., Wong, W.W., Hopkinson, J.M., Heinz, C.J., Mehta, N.R., et al. (2000) Energy Requirements Derived from Total Energy Expenditure and Energy Deposition during the First 2 y of Life. The American Journal of Clinical 
Nutrition, 72, 1558-1569.

[46] Ciampolini, M., Giannellini, V. and Butte, N. (2001) Recognition of Depletion Manifestations (Bearable Hunger) in Infants by Trained Caregivers and Lower Fecal Energy Loss (Abstract). SSIB Annual Meeting, Philadelphia.

[47] Matsuda, M. and DeFronzo, R.A. (1999) Insulin Sensitivity Indices Obtained from Oral Glucose Tolerance Testing: Comparison with the Euglycemic Insulin Clamp. Diabetes Care, 22, 1462-1470. http://dx.doi.org/10.2337/diacare.22.9.1462

[48] Wiesli, P., Schaffler, E., Seifert, B., Schmid, C. and Donath, M.Y. (2004) Islets Secretory Capacity Determines Glucose Homoeostasis in the Face of Insulin Resistance. Swiss Medical Weekly, 134, 559-564.

[49] Ciampolini, M., Bini, S. and Orsi, A. (1996) Microflora Persistence on Duodeno-Jejunal Flat or Normal Mucosa in Time after a Meal in Children. Physiology \& Behavior, 60, 1551-1556. http://dx.doi.org/10.1016/S0031-9384(96)00312-5

\section{Abbreviations}

BG: blood glucose;

IH: Initial Hunger;

IHMP: IH Meal Pattern;

Mean BG: A mean in a sequence of preprandial BGs three times a day for a week or more. Mean BG informs us on the energy balance and on the maintenance of distance from fattening/InsRes in that period;

HBG: high blood glucose;

LBG: low blood glucose. The division between LBG and HBG is at $82 \mathrm{mg} / \mathrm{dL}$ in sedentary people. 